\title{
Effect of Cocaine on Fas-Associated Protein with Death Domain in the Rat Brain: Individual Differences in a Model of Differential Vulnerability to Drug Abuse
}

\author{
María-Julia García-Fuster*,', Sarah M Clinton', Stanley J Watson' and Huda Akil' \\ 'Molecular and Behavioral Neuroscience Institute, University of Michigan, Ann Arbor, MI, USA
}

\begin{abstract}
This study was designed to $(I)$ assess the effects of cocaine on Fas-associated protein with death domain (FADD) system and its role in the activation of apoptotic vs nonapoptotic events and (2) ascertain whether animals selectively bred for their differential propensity to drug-seeking show differences in FADD levels or response to cocaine. Acute cocaine, through $\mathrm{D}_{2}$ dopamine receptors, induced a doseresponse increase in FADD protein in the cortex, with opposite effects over pFADD (Ser | 9|/|94), and no induction of apoptotic cell death (poly-(ADP-ribose) polymerase cleavage). FADD was increased by cocaine in cytosol ( 142\%), membranes ( 23\%) and nucleus ( $\sim 54 \%)$. The modulation of the FADD system showed tolerance of the acute effect over time, as well as a compensatory response on withdrawal that mirrored the acute effect-ie a transient FADD decrease on day 3 of withdrawal, both at mRNA and protein levels. In a second experiment, possible FADD differences were investigated in rats selectively bred for differential responsiveness to novelty, propensity for drug-seeking and cocaine sensitization. High-responders (HR), who were more prone to drug abuse, exhibited higher FADD and lower pFADD levels than low-responder (LR) rats. However, HR and LR rats showed similar rates of cocaine-induced apoptosis, and exhibited a parallel impact of cocaine over FADD within each phenotype. Thus, FADD is a signaling protein modulated by cocaine, regulating apoptosis/proliferative mechanisms in relation to its FADD/pFADD content. Interestingly, animals selectively bred for differential propensity to substance abuse show basal differences in the expression of this protein, suggesting FADD may also be a molecular correlate for the HR/LR phenotype.

Neuropsychopharmacology (2009) 34, I |23-I |34; doi:I0.1038/npp.2008.88; published online 25 June 2008
\end{abstract}

Keywords: cocaine; FADD; apoptosis; proliferation; HR/LR phenotype; rat brain

\section{INTRODUCTION}

Cocaine is a highly abused psychostimulant that poses an enormous health, social, and economic burden on modern society. Cocaine addiction is both mental and physical, and largely depends on drug-induced neurochemical, structural, and behavioral brain alterations (Nestler, 2005). Indeed, a major focus in the field of addiction research has been to understand the early neural changes set in motion soon after the exposure to cocaine, because it is believed that such alterations can set the stage for long-lasting modifications of brain structure and function. Although different drugs of abuse have unique and specific mechanisms of action, similar molecular pathways likely mediate common functional effects (Nestler, 2005). Accordingly, different drugs of abuse share the property of increasing dopamine (DA) in limbic and motor brain areas, which has been

*Correspondence: Dr MJ García-Fuster, Molecular and Behavioral Neuroscience Institute, University of Michigan, 205 Zina Pitcher Place, Ann Arbor, MI 48I09-0720, USA, Tel: + I 734764 9383, Fax: + I 734 647 4I30, E-mail: juliag@umich.edu

Received 8 February 2008; revised 2 May 2008; accepted I 5 May 2008 related to their addictive properties (Wise and Bozarth, 1985; Di Chiara and Imperato, 1988; Beitner-Johnson and Nestler, 1991).

Although effects on neurotransmission are clearly relevant, the impact of drugs of abuse on processes that affect neural plasticity are important to understand both shortand long-term consequences of drug exposure (Robinson and Kolb, 2004; Kalivas, 2007). In mammals, the regulation of cell fate to either proliferate, differentiate, arrest cell growth, or initiate cell death is the most fundamental mechanism for maintaining cellular function and homeostasis. In the developing and adult nervous system, these processes are regulated by complex interactions between several growth factors, neurotransmitters, and neuropeptides (Cameron et al, 1998; Sommer and Rao, 2002). Abundant evidence suggests that either necrotic or apoptotic neuronal death may underlie drug abuse-related behavioral changes (Cunha-Oliveira et al, 2006), although the literature concerning cocaine neurotoxicity in adult brain remains inconclusive (Dietrich et al, 2005).

In various cell systems, Fas-associated protein with death domain (FADD) stimulation, an adaptor protein that senses a death receptor signal and nucleates the death-inducing 
signaling complex (DISC), is associated either with the activation of effector caspases leading to cell apoptosis or with survival/proliferation signals (Park et al, 2005; Peter et al, 2007). FADD also contributes to a number of nonapoptotic processes, including T-cell proliferation (Zhang et al, 1998), T-cell proliferation and/or survival (Beisner et al, 2003), and homeostatic proliferation (Zhang et al, 2005). In the central nervous system (CNS), Fas/FADD stimulation promotes neurite outgrowth (Desbarats et al, 2003) and neuronal branching (Zuliani et al, 2006) through ERK activation. Therefore, FADD is instrumental in controlling a variety of intracellular processes that regulate cell growth/survival/ apoptosis in a complex dance of changing partners and overlapping steps. Indeed, other drugs of abuse (ie opiates) have recently been shown to promote either survival or proliferating neural signals (Tegeder and Geisslinger, 2004; Barry and Zuo, 2005) perhaps through inhibition of FADD by a mechanism dependent on the activation of the antiapoptotic ERK1/2 signaling pathway (Garcia-Fuster et al, 2007).

The present study assessed whether (1) FADD modulation is drug specific (opiate drugs; Garcia-Fuster et al, 2007) or is associated with common neuroplastic mechanisms induced by multiple drugs of abuse (cocaine in this study); (2) cocaine's impact on FADD shifts cell fate toward apoptotic mechanisms (drug-induced neurotoxicity measured by poly-(ADP-ribose) polymerase (PARP) enzyme cleavage, a molecular cell death marker involved in DNA damage following caspase-3 activation (Cagnol et al, 2006)) or nonapoptotic mechanisms; and (3) the activation and/or imbalance of these pathways could underlie a new potential mechanism relevant to the early neural changes instigated by different drugs of abuse.

To address the functional relevance of FADD modulation by cocaine, the second phase of this study assessed whether animals with differential propensity to drug-seeking show a differential FADD response to cocaine. We used a model which shows that rats' locomotor activity in the mild stress of a novel environment predicts subsequent behavioral responses to psychostimulants (Piazza et al, 1989; Piazza and Le Moal, 1996). High-responders rats (HR), exhibit high rates of novelty-induced locomotor activity, display exaggerated behavioral sensitization to psychostimulants, and will self-administer these drugs more readily than lowresponders rats (LR) (Piazza et al, 1989; Pierre and Vezina, 1997; Marinelli and White, 2000; Kabbaj and Akil, 2001). Some of the known HR/LR neurochemical differences (ie dopaminergic) (Piazza et al, 1991; Dietz et al, 2005) that may contribute to their drug-taking behavior lead us to hypothesize certain HR/LR differences in FADD. As the HR/ LR model is one of differential vulnerability to drug-seeking behavior, it was of particular interest to ascertain whether these animals would exhibit basal differences in FADD content, and whether they would show differential reactivity post-cocaine exposure. Stated differently, would measures of FADD signaling reflect a vulnerability trait, drug responsiveness, or an interaction between them?

\section{MATERIALS AND METHODS}

\section{Animals}

Commercially purchased rats. Male Sprague-Dawley rats (Charles River, Wilmington, MA), weighing 225-250 g on arrival were used. Animals were housed three per cage, kept on a 12-h light/dark cycle (lights on at 0700 hours) with controlled temperature and humidity and maintained in accordance with the University of Michigan Committee on the Use and Care of Animals. Food and water were available ad libitum. Rats were allowed to acclimatize to housing conditions for 1 week before drug treatment or testing.

Selectively bred $H R / L R$ rats. Our laboratory recently began to selectively breed HR and LR lines of Sprague-Dawley rats that show reliable differences across multiple behavioral and neurobiological dimensions. Selectively bred HR and LR male rats (fifteenth generation) were used ( $n=4-5$ per group). A description of the breeding strategy and initial behavioral characterization of the HR and LR lines has been published (Stead et al, 2006).

Adult selectively bred $\mathrm{HR}$ and LR male rats weighing 225-250 g were first screened to determine their locomotor response to novelty. Horizontal and rearing activity was monitored by computer in $5 \mathrm{~min}$ intervals over $60 \mathrm{~min}$ by placing animals into clear acrylic $43 \times 21.5 \times 25.5 \mathrm{~cm}$ (high) cages equipped with infrared photocell emitters mounted 2.3 and $6.5 \mathrm{~cm}$ above the grid floor. All testing was performed between 0800 and 1130 am. Total locomotion scores for each rat were calculated by adding the total number of horizontal and rearing movements. HR animals whose scores fell one standard deviation below the HR group average and LR animals whose scores fell one standard deviation above the group average were not used for the subsequent cocaine-treatment study.

\section{Drug Treatment}

Single injection. The dose-response profile was analyzed, with purchased rats receiving a single injection of cocaine at different doses $(3,7.5,15,30 \mathrm{mg} / \mathrm{kg}$, i.p.); animals were killed by decapitation $1 \mathrm{~h}$ after the single administration. To evaluate the role of dopaminergic receptors in the acute cocaine-induced FADD modulation, selective blockers of $D_{1}$ (SCH 23390; $0.5 \mathrm{mg} / \mathrm{kg}$, i.p.) and $\mathrm{D}_{2}$ (raclopride; $0.5 \mathrm{mg} / \mathrm{kg}$, i.p.) DA receptors were administered $30 \mathrm{~min}$ before treatment with cocaine $(7.5 \mathrm{mg} / \mathrm{kg}, 1 \mathrm{~h}$, i.p.), alone, or concomitantly. In all treatments control rats received saline (0.9\% NaCl, $1 \mathrm{ml} / \mathrm{kg}$, i.p.).

Repeated injections. The chronic cocaine study used a treatment regimen known to induce behavioral sensitization (Gosnell, 2005). Thus, one group of commercially purchased animals received injections of $15 \mathrm{mg} / \mathrm{kg}$ cocaine (i.p.), whereas the control group of animals received saline for 7 consecutive days. The acute cocaine group received 6 days of saline and an acute cocaine injection $(15 \mathrm{mg} / \mathrm{kg}$, i.p.) on day 7. All animals were transferred to an adjacent room to receive their daily injections (around 1000 hours) and were then returned to their colony room. On day 7, animals were killed $45 \mathrm{~min}$ following the last injection between 0800 and 1300 hours. After this chronic treatment, the impact of cocaine during the early days of withdrawal was assessed at three time points: days 1, 3, and 7 .

Cocaine treatments with selectively bred HR/LR animals. Selectively bred HR and LR rats (fifteenth generation) were 
used to determine basal HR/LR differences in FADD, pFADD, and PARP protein contents. As previous studies demonstrated that HR/LR rats exhibit distinct behavioral responses to cocaine, the effects of acute $(15 \mathrm{mg} / \mathrm{kg}$, i.p.), chronic (see paradigm above), and cocaine withdrawal (day 3) on FADD content were also studied to ascertain whether differing degrees of cocaine sensitization could be associated with differences in FADD levels.

\section{Tissue Collection}

Animals were killed at the indicated times and the brains removed. The right-half brain was freshly dissected (parietooccipital cortex), fast frozen, and then stored at $-80^{\circ} \mathrm{C}$ until use for western blot experiments (protein content), and the left-half brain was fast frozen and stored at $-80^{\circ} \mathrm{C}$ for in situ hybridization experiments (ISH, mRNA levels).

\section{Cocaine Effect on the Subcellular Distribution of FADD}

The subcellular localization (cerebral cortex) and the effect of cocaine $(7.5 \mathrm{mg} / \mathrm{kg}$, i.p., $1 \mathrm{~h})$ on the content of FADD in the different compartments was monitored by use of the Subcellular Proteome Extraction Kit (ProteoExtract; Calbiochem, Darmstadt, Germany) as per the manufacturer's instructions (Garcia-Fuster et al, 2007). This sequential extraction method relies on the different solubility of proteins in certain subcellular compartments to yield four subproteomes enriched in cytosolic (F1), membrane and membrane organelle-localized (F2), soluble and DNAassociated nuclear (F3), and cytoskeletal (F4) proteins. The efficiency and selectivity of this subcellular extraction procedure have been reported (Abdolzade-Bavil et al, 2004), and in the current study, the assay's selectivity was assessed by the immunodetection of neurofilament (NF-L) protein, a specific cytoskeletal marker of mature neurons, which was only identified in F4 (Garcia-Fuster et al, 2007).

\section{Sample Preparations, Immunoblot Assays, and Quantitation of Target Proteins}

Brain tissue samples (right-half cerebral cortex) were prepared in the presence of various protease inhibitors as previously reported (Garcia-Fuster et al, 2007). Aliquots of total homogenate were mixed with equal volumes of electrophoresis loading buffer, denatured, and stored at $-20^{\circ} \mathrm{C}$ until use. Protein concentrations were determined by the BCA Protein Assay (Pierce, IL). In routine experiments, brain proteins $(40 \mu \mathrm{g})$ were separated under nonreducing conditions on 10\% SDS-PAGE minigels (Bio-Rad Laboratories, Hercules, CA), which was followed by standard immunoblotting procedures (Garcia-Fuster et al, 2003).

The primary antibodies used (overnight incubation at $4^{\circ} \mathrm{C}$ ) were: anti-FADD (H-181) (affinity-purified rabbit polyclonal antibody raised against human FADD C-terminal 28-208 residues; dilution 1:5000; sc-5559, batch J-2004; Santa Cruz Biotechnology, USA); anti-p-Ser191 FADD (affinity purified rabbit polyclonal antibody raised against residues surrounding p-Ser191 of mouse FADD; oligomeric forms; dilution 1:750; Lot No 1; Cell Signaling Technology, Beverly, MA); anti-PARP (rabbit polyclonal antibody raised against a peptide corresponding to amino acids $215-228$ of human PARP; dilution 1:800; bacth B76146; Calbiochem); anti-NF-L (mouse monoclonal antibody; dilution 1:500; clone NR4, batch 094K4815; Sigma Chemical Co., St Louis, $\mathrm{MO}$ ); and anti- $\beta$-actin (mouse monoclonal antibody; dilution 1:10000; clone AC-15, batch 045K4831; Sigma). The secondary antibody, horseradish peroxidase-linked anti-rabbit or anti-mouse IgG, was incubated at dilution 1:5000 in blocking solution at room temperature for $1 \mathrm{~h}$.

Immunoreactivity of target proteins was detected with an ECL Western Blot Detection system (Amersham International, Buckinghamshire, UK) and visualized by exposure to Hyperfilm ECL film (Amersham) for $60 \mathrm{~s}$ to $60 \mathrm{~min}$ (autoradiograms). The autoradiograms were quantified by densitometric scanning (IOD) using NIH Image software. The amount of target proteins in brain samples of treated rats was compared in the same gel with that of control rats, which received saline. This procedure was assessed 3-6 times in different gels (each gel with different samples from saline- and drug-treated rats). Finally, percent changes in immunoreactivity with respect to control samples (100\%) were calculated for each rat treated with the specific drug in the various gels and the mean value used as a final estimate. The content of $\beta$-actin (a cytoskeletal protein not altered in brain by cocaine treatments; Imam et al, 2005; Fumagalli et al, 2006; Zhang et al, 2007) was quantified as a loading control.

\section{In Situ Hybridization Histochemistry}

The ISH method used in this study is described in detail by Isgor et al, 2003. Cocaine-induced changes in mRNA levels were detected in the brain cortex ( $\mathrm{S} 1 \mathrm{Tr}$, bregma $-3.60 \mathrm{~mm}$ ). Briefly, tissue (left-half brain) was cryostat-sectioned (at $\left.-20^{\circ} \mathrm{C}, 10 \mu \mathrm{m}\right)$ and mounted onto poly(L-lysine)-coated slides, and stored at $-80^{\circ} \mathrm{C}$ until use. Before probe hybridization, tissue was fixed in $4 \%$ paraformaldehyde at room temperature, rinsed with aqueous buffers, and dehydrated with graded alcohols. After air-drying, the sections were hybridized with an ${ }^{35}$ S-labeled cRNA probe. The following probes were cloned from cDNA fragments with specific primers using standard in vitro transcription methodology: FADD (542 nucleotide fragment directed against the rat FADD mRNA coding region, nucleotides $355-898$ ); $\beta$-actin (633 nucleotide fragment directed against the rat $\beta$-actin mRNA coding region, nucleotides 211-844). The probes were labeled with incorporation of ${ }^{35} \mathrm{~S}$-UTP and ${ }^{35} \mathrm{~S}$-CTP and hybridized to tissue overnight at $55^{\circ} \mathrm{C}$. The next day, sections were washed with increasing stringency, dehydrated with graded alcohols, air-dried, and exposed to film. Film exposure time was chosen to maximize signal. Digital images of the brain sections were scanned and integrated optical density was measured using an image analysis system (Scion Image). The specificity of the hybridization signal was confirmed with sense probe controls for both probes (data not shown).

\section{Data and Statistical Analysis}

All series of data were analyzed with the program GraphPad Prism, version 3.0. Results are expressed as mean values \pm standard error of the mean (SEM). One- or two-way analysis of variance (ANOVA) followed by Bonferroni's multiple 
comparison tests and Student's one- or two-tailed $t$-test were used for the statistical evaluations. The level of significance was chosen as $p \leqslant 0.05$.

Planned comparisons of main effects were employed and justified given the a priori hypothesized greater vulnerability to cocaine (degree of cocaine sensitization) of HR relative to LR phenotype (Kabbaj, 2006) regardless of the presence of significant two-way interaction terms.

\section{Drugs and Chemicals}

Cocaine- $\mathrm{HCl}$ was obtained from Mallinckrodt Inc. (St Louis, MO) and $\mathrm{R}(+)$-SCH-23390 $\mathrm{HCl}$ and S(-)-Raclopride(+)tartrate salt were purchased from Sigma. PARP Cleavage Detection Kit was obtained from Calbiochem. Other materials were purchased from Amersham, Santa Cruz Biotechnology and Sigma-Aldrich.

\section{RESULTS}

\section{Studies with Commercially Purchased Outbred Rats}

Acute effects of cocaine on FADD and pFADD protein content in rat brain cortex: lack of apoptosis measured by PARP cleavage enzyme. There was a main effect of cocaine treatment on FADD content $(\mathrm{F}(4,22)=11.39$, $p<0.0001)$. Acute cocaine treatment $(3-30 \mathrm{mg} / \mathrm{kg}$, i.p., $1 \mathrm{~h})$ induced complex effects on FADD content with an inverted U-shape dose-response curve $(3 \mathrm{mg} / \mathrm{kg}, 14 \pm 5 \%$ decrease, n.s.; $7.5 \mathrm{mg} / \mathrm{kg}, \quad 46 \pm 5 \%$ increase, $p<0.001 ; 15 \mathrm{mg} / \mathrm{kg}$, $35 \pm 10 \%$ increase, $p<0.05$; and $30 \mathrm{mg} / \mathrm{kg}, 19 \pm 4 \%$ increase, n.s.) in the cerebral cortex (total homogenate) compared to vehicle-treated animals (Figure 1a). FADD phosphorylation at Ser 191/194 is the principal mechanism by which this multifunctional adaptor protein regulates its nonapoptotic activities (Alappat et al, 2005). There was also a main effect of cocaine on pFADD protein content $(\mathrm{F}(3,20)=5.347$, $p=0.0072)$. Acute cocaine treatment $(7.5-30 \mathrm{mg} / \mathrm{kg}$, i.p., $1 \mathrm{~h}$ ) decreased the immunodensity of pFADD (Ser 191) at all doses tested: $7.5 \mathrm{mg} / \mathrm{kg}, 19 \pm 5 \% \quad(p<0.001) ; 15 \mathrm{mg} / \mathrm{kg}$, $14 \pm 3 \%(p<0.05)$; and $30 \mathrm{mg} / \mathrm{kg}, 6 \pm 2 \%$ (n.s.) (Figure $1 \mathrm{~b}$ ). None of the cocaine treatments significantly altered $\beta$-actin content (Figures 1a and $\mathrm{b}$ ).

As cocaine treatment increased FADD content (proapoptotic), the effect of cocaine exposure on PARP enzyme that is involved in DNA damage following DNA nicks was also investigated as a molecular marker of cell death (Cagnol et al, 2006). Acute cocaine treatment $(7.5,15$, and $30 \mathrm{mg} / \mathrm{kg}$, i.p., $1 \mathrm{~h}$ ) did not alter the pattern of PARP cleavage $(\sim 85 \mathrm{kDa}$ fragment) observed in the cerebral cortex of vehicle-treated rats $(\mathrm{F}(7,40)=0.4964, p=0.8315$, n.s.; Figure 1c), which indicated that a differential rate of cell death mediated by PARP cleavage was not activated by cocaine under the reported experimental conditions.

Effect of acute cocaine on the subcellular localization of FADD in rat brain cortex. Given that FADD was found to be induced by the cocaine treatment, its precise cellular localization was next examined. FADD in the cerebral cortex and at the subcellular level showed a similar pattern of subcellular distribution as previously reported (see Garcia-Fuster et al, 2007). Thus, FADD was abundantly localized in association with membranes (F2) and in the nucleus (F3), to a lesser extent in cytosol (F1), with no detectable levels in the cytoskeletal compartment (F4) (Figure 2). Acute cocaine $(7.5 \mathrm{mg} / \mathrm{kg}, 1 \mathrm{~h}$, i.p.) increased FADD protein content in all the compartments where it was expressed (given the expected increase in FADD by cocaine a one-tailed $t$-test was performed for each fraction): by $142 \pm 60 \%$ in the cytosol $(\mathrm{F}(2,4)=8.190 ; p<0.05)$; by $23 \pm 5 \%$ in membranes $(\mathrm{F}(2,4)=2.803 ; p<0.05)$; and by $54 \pm 30 \%(\mathrm{~F}(2,4)=2.536 ; p=0.1$, n.s., all three animals increased FADD) in the nuclear fraction (Figure 2), indicating that FADD changes in total cerebral cortex homogenate reflects its regulation in key cellular compartments. As expected, NF-L was only expressed in the cytoskeletal compartment (F4). $\beta$-actin showed different relative protein contents per subcellular fraction, but its expression levels were not affected in any fraction following cocaine exposure. The graph in Figure 2 shows the ratio of $\mathrm{FADD} / \beta$-actin (IOD) for each fraction.

Effects of chronic cocaine and cocaine withdrawal on FADD content in rat brain cortex. In contrast to the acute effects of cocaine on FADD ( $49 \pm 14 \%$ increase, $p<0.001)$, there were no significant changes after chronic cocaine treatment $(15 \mathrm{mg} / \mathrm{kg}$, i.p., 7 days) on FADD protein content $(7 \pm 4 \%$ increase, n.s.). There was a main effect of cocaine withdrawal on FADD $(F(5,46)=10.83, p<0.0001)$, which led to the inverse effect previously seen with acute cocaine administration, with a progressive decrease in FADD reaching a nadir at 3 days post-cocaine and reversing thereafter (day 1, $18 \pm 7 \%$ decrease, n.s.; day 3, $27 \pm 6 \%$ decrease, $p<0.05$; and day 7 , $9 \pm 3 \%$ decrease, n.s.; Figure 3a). None of these treatments significantly altered $\beta$-actin content (Figure $3 a$ ).

At the mRNA level, parallel changes were observed after chronic cocaine treatment $(8 \pm 8 \%$ decrease, n.s. $)$ and cocaine withdrawal leading to a decrease in gene expression most notable after 3 days of withdrawal (day 1, $24 \pm 3 \%$ decrease, $p<0.05$; day 3, $30 \pm 3 \%$ decrease, $p<0.01$ and day $7, \quad 17 \pm 5 \%$ decrease, n.s. $\quad(\mathrm{F}(4,25)=6.198, p=0.0013$; Figure $3 \mathrm{~b}$ ). Indeed, there was a positive and significant correlation between the protein and mRNA FADD levels $(r=0.43 ; n=29 ; p<0.02)$ in the same cerebral cortices (Figure 3c), indicating that spontaneous withdrawal from chronic cocaine remarkably decreased FADD both at the transcriptional and post-translational level. The mRNA expression of $\beta$-actin was not altered with any of these treatments (data not shown), which is consistent with previous results (Yamaguchi et al, 2005).

$D_{2} D A$ receptors influence $F A D D$ activation by cocaine in rat brain cortex. Pretreatment of rats with raclopride (a $\mathrm{D}_{2}$-type receptor antagonist; $0.5 \mathrm{mg} / \mathrm{kg}$, i.p.) $30 \mathrm{~min}$ before cocaine fully prevented the acute cocaine-induced increase of $\operatorname{FADD}(\mathrm{F}(3,27)=7.522, p=0.0008$; Figure $4 \mathrm{a})$. However, pretreatment of rats with SCH-23390 (a D $\mathrm{D}_{1}$-type receptor antagonist; $0.5 \mathrm{mg} / \mathrm{kg}$, i.p.) $30 \mathrm{~min}$ before cocaine did not block the acute cocaine-induced increase of FADD (Figure $4 \mathrm{~b})$. Indeed, $\mathrm{SCH}-23390$ alone $(0.5 \mathrm{mg} / \mathrm{kg}$, i.p., $1 \mathrm{~h} 30 \mathrm{~min})$ induced an increase $(40 \pm 9 \%, p<0.05$; $\mathrm{F}(3,14)=7.887)$ in FADD content in the cerebral cortex. None of these treatments significantly altered $\beta$-actin content (Figure 4). 

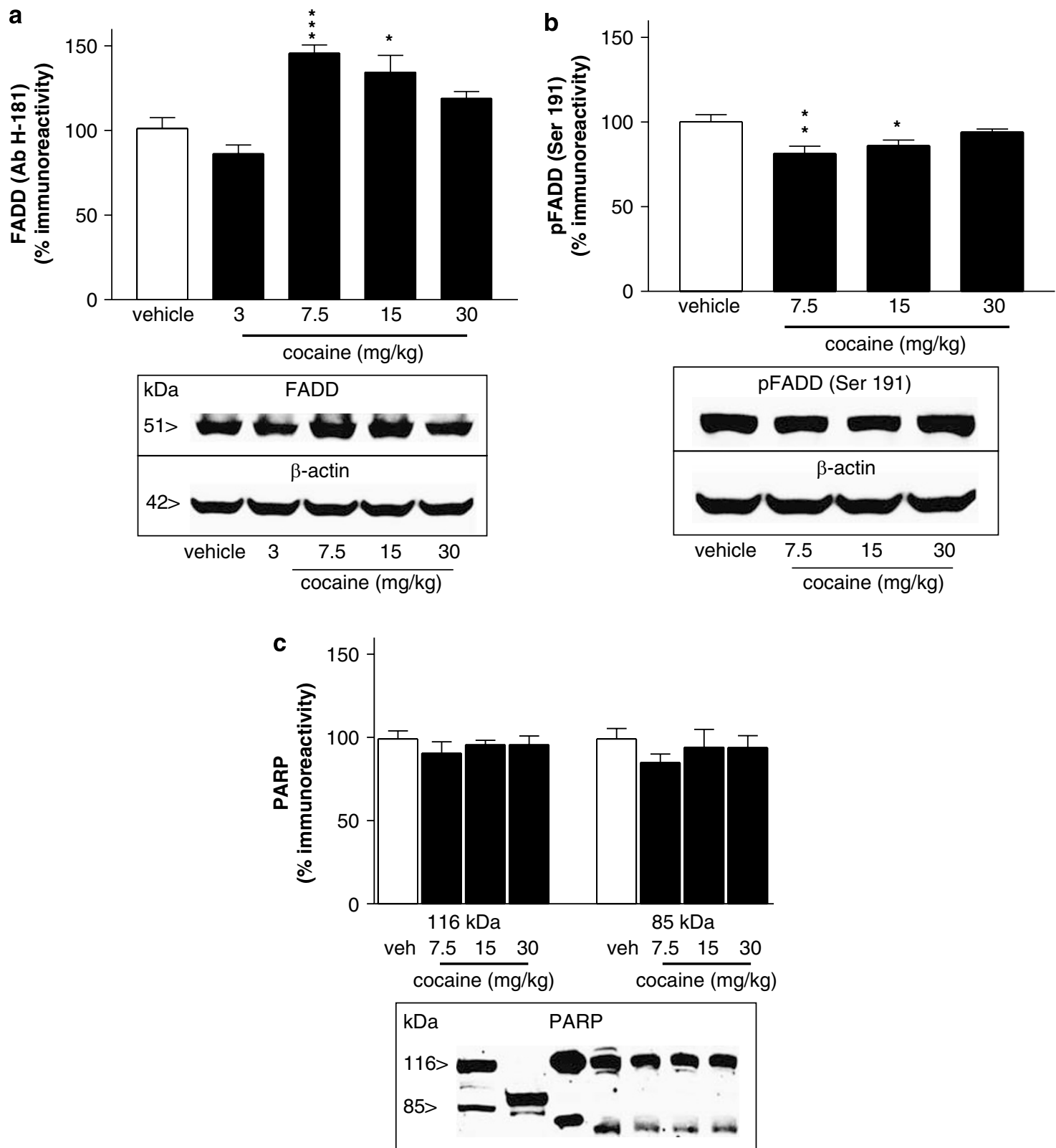

NC PC Std veh $7.5 \quad 15 \quad 30$

Figure I Acute effects of cocaine on Fas-associated protein with death domain (FADD) and pFADD in rat brain cortex: lack of apoptosis measured by poly-(ADP-ribose) polymerase (PARP) cleavage. (a) FADD protein content. This experiment was composed of two sets of experiments: $(I)$ vehicle ( $n=6$ ), cocaine (7.5, I5, and $30 \mathrm{mg} / \mathrm{kg}$, i.p., $60 \mathrm{~min} ; n=6$ each) and (2) vehicle $(n=3)$, cocaine ( $3 \mathrm{mg} / \mathrm{kg}$, i.p., $60 \mathrm{~min} ; n=3)$. Both sets of experiments were combined for the statistical analysis of FADD protein content. Columns are means \pm standard error of the mean (SEM) per group and expressed as percentage of vehicle-treated rats. One-way analysis of variance (ANOVA) detected a significant difference between the groups of treatments $(F(4,22)=11.39$, $p<0.000$ I). * $p<0.05$; **** $<0.00$ I vs control (ANOVA followed by Bonferroni's test). (b) pFADD protein content. Groups of treatments: vehicle ( $n=6$ ), cocaine $(7.5,15$, and $30 \mathrm{mg} / \mathrm{kg}$, i.p., $60 \mathrm{~min}, n=6$ each). ANOVA $(F(3,20)=5.347, p=0.0072)$ : *** $p<0.01$; * $p<0.05$ vs control. (a-b, bottom) Representative immunoblots of FADD and PFADD and the corresponding for $\beta$-actin as a loading control (sample: $40 \mu \mathrm{g}$ protein). (c) PARP cleavage. Groups of treatments: vehicle $(n=6)$, cocaine $(7.5,15$, and $30 \mathrm{mg} / \mathrm{kg}$, i.p., $60 \mathrm{~min}, n=6$ each). One-way ANOVA did not detect a significant difference between the groups of treatments $(F(7,40)=0.4964, p=0.83$ I 5 , n.s.). Bottom: representative immunoblot of PARP (sample: $40 \mu g$ protein). NC, negative control (whole extract of human HL60 leukemia cells, basal rates of apoptosis); PC, positive control (etoposide-induced apoptosis in HL60 cells, PARP molecules fragmented); Std, PARP protein standard. The apparent molecular masses were determined by calibrating the blots with prestained molecular weight markers as shown on the left-hand side.

\section{Studies with Selectively Bred HR/LR Rats}

Basal HR/LR differences in FADD/PFADD and PARP. HR/LR rats showed differences in basal FADD and pFADD
(Ser 191) protein content with HR exhibiting higher FADD levels $(45 \pm 8 \%$ change, $p<0.01 ; \mathrm{F}(1,8)=1.593$; Figure $5 \mathrm{a}$ ) and lower levels of pFADD (Ser 191) (17 $\pm 6 \%$ change, $p<0.05 ; \mathrm{F}(1,6)=2.586$; Figure $5 \mathrm{~b})$ compared to LR rats. 


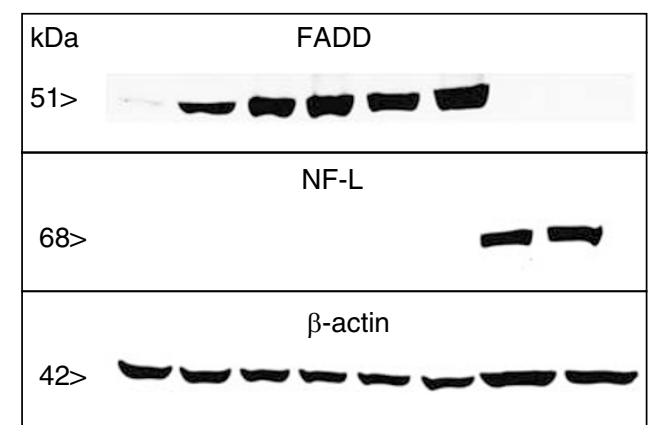

$\frac{\text { veh coc }}{\mathrm{F} 1} \frac{\text { veh coc }}{\mathrm{F} 2} \frac{\text { veh coc }}{\mathrm{F} 3} \frac{\text { veh coc }}{\mathrm{F} 4}$

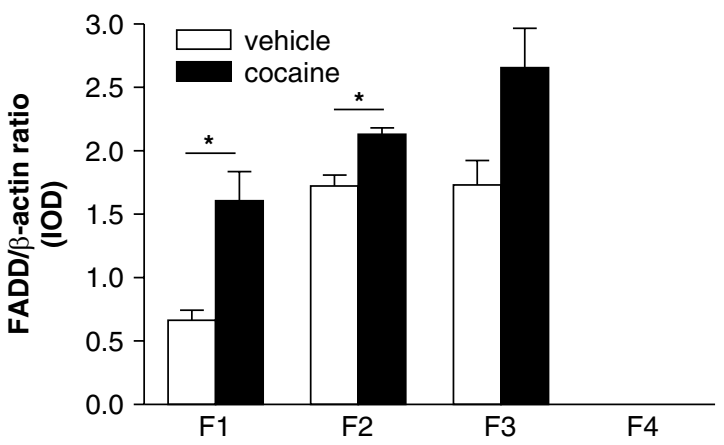

Figure 2 Representative immunoblot depicting the subcellular localization of Fas-associated protein with death domain (FADD) and the acute effect of cocaine $(7.5 \mathrm{mg} / \mathrm{kg}$, i.p., $60 \mathrm{~min})$ on FADD content in various subcellular compartments of the rat cerebral cortex (FI, cytosol; F2, membrane/organelle; F3, nucleus; F4, cytoskeletal proteins; $40 \mu \mathrm{g}$ protein for FI-F3 fractions and $20 \mu \mathrm{g}$ protein for F4; see Materials and Methods for further details). Given the expected increase in FADD by cocaine a onetailed $t$-test was performed for each fraction. Note that cocaine tends to increase FADD content in the cytosolic ( $F I$ by I $42 \pm 60 \% ; F(2,4)=8.190$; $* p<0.05$ ), membranal ( $F 2$ by $23 \pm 5 \% ; F(2,4)=2.803$; $* p<0.05$ ), and nuclear ( $\mathrm{F} 3$ by $54 \pm 30 \% ; F(2,4)=2.536 ; p=0.1$, n.s.) fractions. In the cytoskeletal fraction (F4) FADD was not immunodetected. Immunoblots of neurofilament (NF-L) proteins and $\beta$-actin were immunodetected in FI-F4. Note that NF-L was immunodetected in F4 but not in the other subcellular fractions. $\beta$-actin was not significantly changed in each fraction even though, as expected, the protein showed different relative protein contents per fraction. In fact, the ratio FADD/ $\beta$-actin (IOD) \pm standard error of the mean (SEM) was calculated for each fraction and a bar graph was represented with the results (see bar graph). This experiment was repeated 2-3 times with similar results. The apparent molecular masses were determined as indicated in Figure I.

There were no significant differences in the basal pattern of PARP $(116 \mathrm{kDa})$ cleavage $(\sim 85 \mathrm{kDa}$ fragment) for the HR/LR phenotype $(F(3,15)=0.7523, p=0.5379$; Figure $5 c)$, indicating no different rates of basal induction of apoptotic cell death in the HR/LR phenotypes. There were no differences in the content of $\beta$-actin that was used as a loading control (Figure 5).

To further examine HR/LR differences in basal FADD and pFADD protein content, a correlation analysis of rats' novelty-induced locomotion scores and FADD (Figure 5d) or pFADD (Figure 5e) protein levels was performed. This analysis revealed a significant positive correlation between locomotion scores and FADD protein $(r=0.84 ; n=10$; $p<0.003)$ and a significant negative correlation with pFADD $(r=-0.76 ; n=10 ; p=0.01)$ in the same cerebral cortices (HR/LR vehicle-treated rats) (Figures $5 \mathrm{~d}$ and e).
$F A D D$ is not differentially regulated in $H R / L R$ rats following repeated cocaine and cocaine withdrawal. Similar to findings in HR/LR control animals, cocainetreated HR/LR rats also showed baseline differences in FADD protein content, with HR rats exhibiting higher FADD levels than LR rats ( $39 \%$ change, $p=0.0002$, two-way ANOVA followed by Bonferroni's post hoc test; Figure 6). There was also a main effect for cocaine over FADD within each phenotype (LR rats: $\mathrm{F}(3,15)=12.77, p<0.001$; HR rats: $\mathrm{F}(3,14)=8.745, p<0.01)$, which paralleled the findings previously observed with commercially purchased rats - ie acute cocaine treatment increased FADD (LR rats: $35 \pm 9 \%$ increase, $p<0.05$; HR rats: $29 \pm 8 \%$ increase, $p<0.05)$ with a reversal following 3 days of withdrawal (LR rats: $25 \pm 8 \%$ decrease, $p<0.05$; HR rats: $33 \pm 6 \%$ decrease, $p<0.05$ ). However, there was no significant drug treatment phenotype interaction ( $p=0.8567$, n.s.; Figure 6$)$.

\section{DISCUSSION}

The findings reported here characterize the effects of cocaine on the FADD system, and then ask whether inborn differences in propensity to substance abuse may relate to innate differences in the FADD system. These two series of studies are discussed in sequence.

\section{Effects of Cocaine on FADD in the Rat Brain Cortex}

The present results demonstrated that cocaine modulates FADD protein content in the brain as a part of a complex series of neuroplastic molecular mechanisms likely involved in the early stages of the addictive process. Specifically, we showed that (1) acute cocaine modulated FADD forms, increasing overall FADD, decreasing pFADD, with no activation of apoptosis; (2) cocaine treatment increased FADD protein in all subcellular compartments where it was expressed, but shifted FADD distribution, making it more cytosolic. We also observed that (3) repeated cocaine administration induced tolerance to its acute modulatory effect on FADD; (4) cocaine withdrawal was associated with a transient reduction in FADD density (main effect at day $3)$; (5) there was a positive correlation of FADD mRNAprotein levels; and (6) $\mathrm{D}_{2} \mathrm{DA}$ receptors were involved in FADD activation by cocaine. Taken together these data suggest that FADD is modulated by cocaine, that the acute effect is subject to tolerance but also shows an impact of withdrawal in a direction that mirrors the original effect. Thus, this modulation of FADD by cocaine not only has short-term consequences but long-term impact, particularly during the first days of withdrawal.

Concerning the acute modulation of FADD by cocaine, and in regard to its regulation of apoptotic $v s$ nonapoptotic events, we examined the impact of cocaine exposure on the phosphorylated form of FADD, recently described as a nonapoptotic marker (Alappat et al, 2005; Park et al, 2005, 2007; Chen et al, 2005; Bhojani et al, 2005), and PARP, an enzyme cleaved by the protease caspase- 3 , as an apoptotic marker (Cagnol et al, 2006). Acute cocaine treatment induced significant decreases in pFADD protein content, and as judged from levels of PARP protein activation, did not appear to induce apoptosis in the brain cortex, at least 


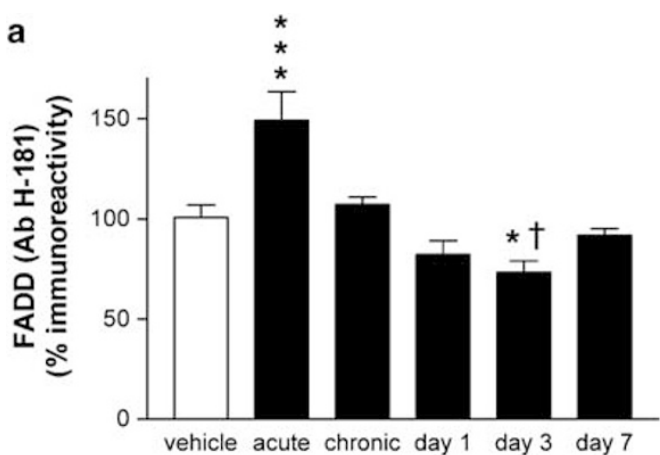

b
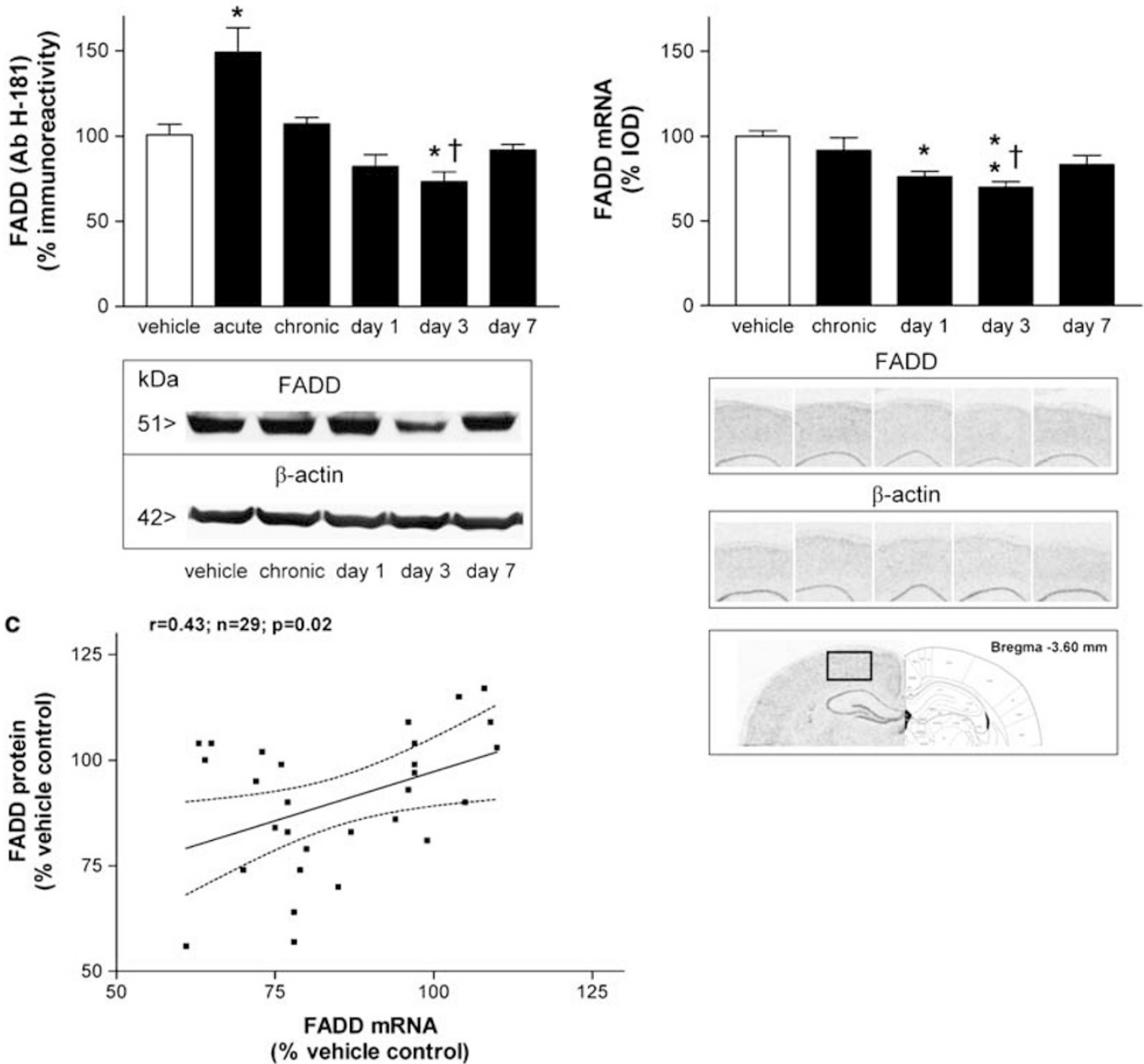

(\% vehicle control)

Figure 3 Effects of chronic cocaine and cocaine withdrawal on Fas-associated protein with death domain (FADD) content (protein and mRNA levels) in rat brain cortex. (a) FADD protein content. This experiment was composed of two sets of experiments: ( 1 ) vehicle ( $n=8)$, acute cocaine (acute, 6 days of saline and on day $7,15 \mathrm{mg} / \mathrm{kg}$ of cocaine; $n=6$ ), and chronic cocaine (chronic, $15 \mathrm{mg} / \mathrm{kg}$ for 7 days; $n=8$ ) and $(2)$ vehicle $(n=6)$, chronic cocaine (chronic, $15 \mathrm{mg} / \mathrm{kg}$ for 7 days; $n=6$ ), and chronic cocaine followed by spontaneous withdrawal (day I, 3, or $7 ; n=6$ each). Both sets of experiments were combined for the statistical analysis at the protein level. Columns are means \pm standard error of the mean (SEM) per group and expressed as percentage of vehicletreated rats. One-way analysis of variance (ANOVA) detected a significant difference between the groups of treatments $(F(5,46)=|0.83, p<0.000|$ ). ${ }^{*} * * * 0.00$ I: * $p<0.05$ vs control; ${ }^{\dagger} p<0.05$ vs chronic cocaine (ANOVA followed by Bonferroni's test). Bottom: representative immunoblots of FADD (second experimental set) and the corresponding for $\beta$-actin as a loading control (sample: $40 \mu \mathrm{g}$ protein). The apparent molecular masses were determined as indicated in Figure I. (b) FADD mRNA. Groups of treatments: animals of the second set of the above experiments. ANOVA $(F(4,25)=6.198, p=0.00 I 3)$. ${ }^{*} p<0.05$; $* * * 0.01$ vs control; ${ }^{\dagger} p<0.05$ vs chronic cocaine. Bottom: representative $X$-ray images of FADD and $\beta$-actin mRNA for each treatment group. An image showing the representative region where the changes were measured is also shown (brain cortex, SI Tr, bregma $-3.60 \mathrm{~mm}$ ). (c) Scatter plot depicting a significant positive correlation between the immunodensity of FADD protein and FADD mRNA in the rat cerebral cortex (same samples, second experimental set) after chronic cocaine (chronic, $15 \mathrm{mg} / \mathrm{kg}$ for 7 days; $n=6$ ) and time course withdrawal (days 1 , 3 , and $7 ; n=6$ each) treatments, and expressed as percentage of the corresponding vehicle-treated rats (controls). Each circle represents a different treated rat. The solid line $(y=0.34 x-180.3)$ is the best fit of the correlation $(r=0.43, F=6.02, n=29, p=0.02)$. The dotted curves indicate the $95 \%$ confidence interval for the regression line.

at the $1 \mathrm{~h}$ time point chosen for this study (see Garcia-Fuster et al, 2007 for FADD time course fluctuation). A previous study showed that opiate drugs also modulate FADD in cortex, but in the opposite direction, leading to decreased FADD content (Garcia-Fuster et al, 2007). These disparate findings may be related to the fact that these drugs, a psychostimulant $v s$ a psychodepressant, exert opposing effects on the CNS. In fact, opiate drugs (and specifically the $\delta$-agonists) could promote survival signals in the brain through inhibition of FADD, which in turn is dependent on the activation of the antiapoptotic ERK1/2 signaling pathway (Garcia-Fuster et al, 2007), crucial for protection against Fas/FADD-mediated apoptosis (Holmstrom et al, 1999, 2000). Other experimental evidence has shown that cocaine alters proliferation, migration, and differentiation of human fetal brain-derived neural precursor cells $(\mathrm{Hu}$ et al, 2006). However, the potential effect of cocaine in inducing apoptosis of mature neurons is controversial. Several in vitro studies suggest that cocaine instigates cell death (reviewed in Cunha-Oliveira et al, 2006; Dey and Snow, 2007), but the majority of in vivo studies focus on prenatal cocaine exposure (Nassogne et al, 1997). Studies in the adult brain have found that cocaine is less neurotoxic compared to other drugs of abuse (eg D-amphetamine, 

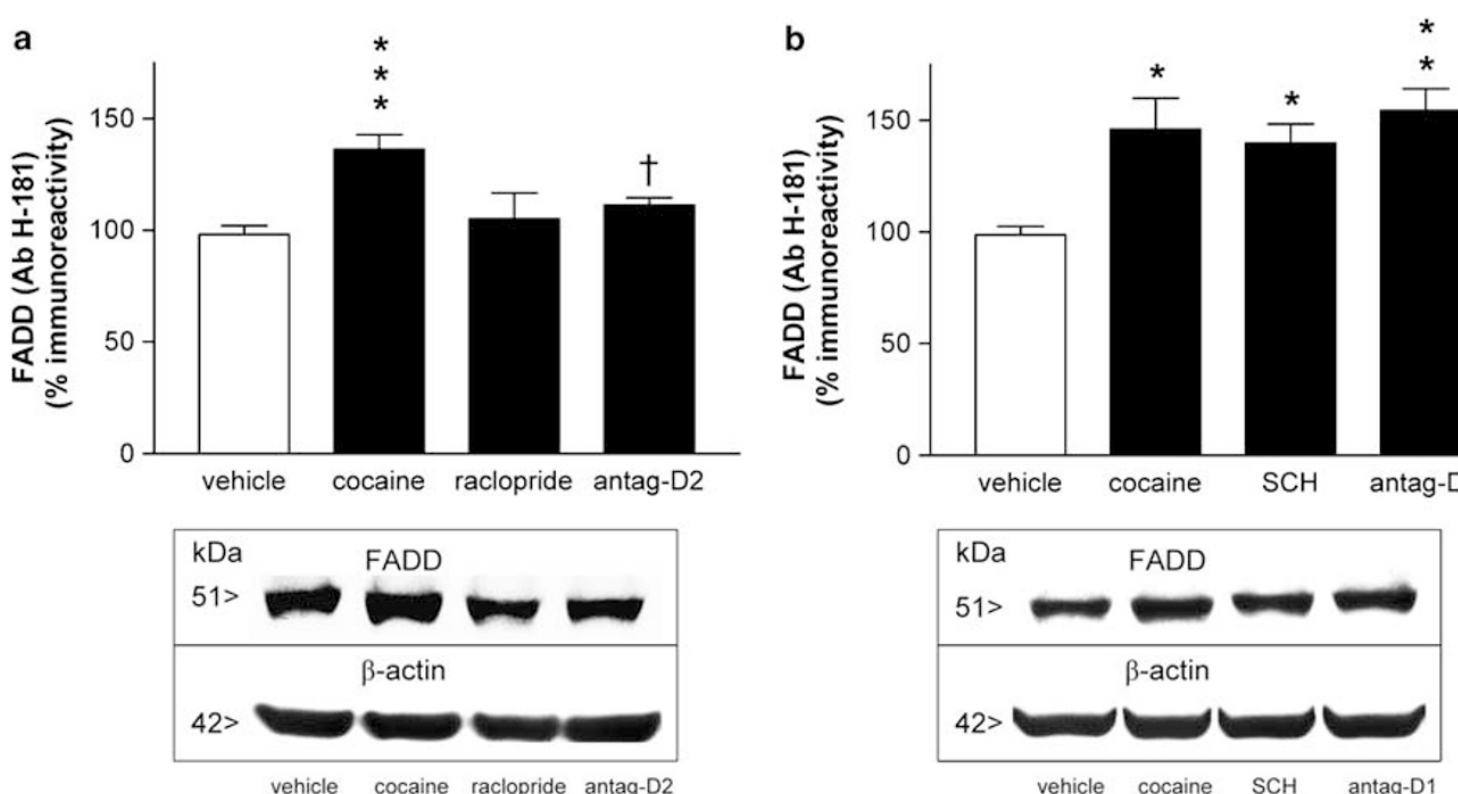

Figure $4 \quad D_{2}$ dopamine (DA)-receptors influence Fas-associated protein with death domain (FADD) activation by cocaine in rat brain cortex (a) $D_{2}$ antagonism by raclopride. Groups of treatments: vehicle $(n=1 \mathrm{l})$, cocaine $(7.5 \mathrm{mg} / \mathrm{kg}$, i.p., $60 \mathrm{~min} ; n=9)$, raclopride $(0.5 \mathrm{mg} / \mathrm{kg}, 90 \mathrm{~min} ; n=6)$, and raclopride + cocaine (antag- $D_{2}, n=5$ ). Columns are means \pm standard error of the mean (SEM) per group and expressed as percentage of vehicle-treated rats. Oneway analysis of variance (ANOVA) detected a significant difference between the groups of treatments $(F(3,27)=7.522, p=0.0008)$ : **** $p<0.00$ I vs control; ${ }^{\top} p<0.05$ vs cocaine. (b) D, antagonism by SCH-23390. Groups of treatments: vehicle $(n=5)$, cocaine $(7.5 \mathrm{mg} / \mathrm{kg}$, i.p., $60 \mathrm{~min} ; n=4), \mathrm{SCH}-23390$ $(\mathrm{SCH}, 0.5 \mathrm{mg} / \mathrm{kg}, 90 \mathrm{~min} ; n=4)$, and $\mathrm{SCH}+$ cocaine (antag- $\left.D_{1}, n=5\right)$. Other details are as above. ANOVA $(F(3, \mid 4)=7.887, p=0.0025)$ : * $p<0.05$ : *** $p<0.0$ I vs control. (a-b, bottom) Representative immunoblots of FADD for each set of experiments, and the corresponding for $\beta$-actin as a loading control (sample: $40 \mu \mathrm{g}$ protein). The apparent molecular masses were determined as indicated in Figure I.

METH, and heroin), and does not appear to mediate any apoptotic events (Dietrich et al, 2005). Thus, based on these facts and on the results of the present study (increase FADD, decrease pFADD, but no apoptotic activation measured by PARP), it is feasible to suggest that cocaine might impair mechanisms controlling nonapoptotic functions (eg cell proliferation and survival), which still suggests a possible neurotoxic effect of the drug.

Several studies in a variety of cell types have reported that FADD is exclusively localized in the cytoplasm (O'Reilly et al, 2004), in the cytoplasm and nucleus (Gomez-Angelats and Cidlowski, 2003; Alappat et al, 2005; Lee et al, 2006; Yoo et al, 2007), or solely within the nucleus (Screaton et al, 2003; Bhojani et al, 2005). However, it is known that upon Fas ligation, cytoplasmic FADD is rapidly recruited to the plasma membrane where it forms, together with Fas and procaspase-8, the so-called DISC (Kischkel et al, 1995; Algeciras-Schimnich et al, 2002). In line with this fact and with a previous study (Garcia-Fuster et al, 2007), the present results showed that FADD protein is mainly expressed in membrane (F2) and nucleus (F3), and to a lesser extent in cytoplasm (F1). Furthermore, acute cocaine exposure not only augmented the content of FADD overall, but also increased the proportion in the cytosolic fraction, indicating an alteration of distribution across cellular compartments.

After chronic cocaine treatment, the overall extent of FADD modulation in cortex was decreased compared with the single injection, presumably reflecting adaptative mechanisms set in motion by the chronic cocaine exposure. In fact, numerous studies have demonstrated that chronic cocaine administration reduces some of the acute drug effects (ie tolerance) and, at the same time, enhances other neuronal responses (ie sensitization; for review see Berke and Hyman, 2000; Nestler, 2004). However, cocaine withdrawal (after 1, 3, and 7 days) following chronic cocaine exposure induced a new time course of downregulation of FADD protein content, with a peak decrease 3 days after the last cocaine dose and a reversal to normal levels after 7 days. Moreover, as previously described for this molecule in rat brain cortex (Bi et al, 2008), there was a positive correlation between FADD mRNA and protein levels after these treatments, suggesting that after spontaneous withdrawal from chronic cocaine, the entire machinery controlling the synthesis of FADD, including both the transcriptional and post-transcriptional level, was downregulated. Thus, there might be multiple time domains of change, some transient and some sustained, some leading to tolerance and some to sensitization, which may led us to associate the rapid modulation of FADD by cocaine with the immediate changes that may show tolerance but are uncovered during the early days of withdrawal. Similarly, many of the known acute and chronic cocaine-induced alterations in gene expression and neurotransmitter systems are transient (Kreek, 1996; Nestler, 2001, 2004), and are hypothesized to represent compensatory adaptations to maintain homeostasis by reducing drug-induced effects.

The current study demonstrated that acute cocaine treatment increased FADD content in the cortex through a DA $\mathrm{D}_{2}$-dependent mechanism, but not through $\mathrm{D}_{1} \mathrm{DA}$ receptors. Similarly, the stimulation of $\mathrm{D}_{2}$, but not $\mathrm{D}_{1}, \mathrm{DA}$ receptors induced a marked increase in FGF-2 expression in the striatum and cortex (Roceri et al, 2001; Fumagalli et al, 2003). The present study also showed that $D_{1} D A$ 
a
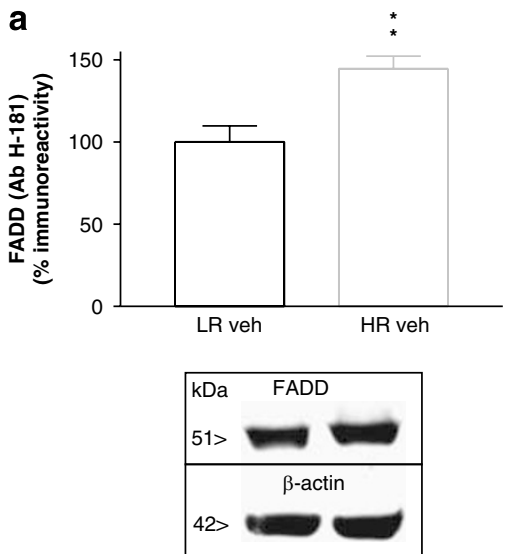

LR veh HR veh

d

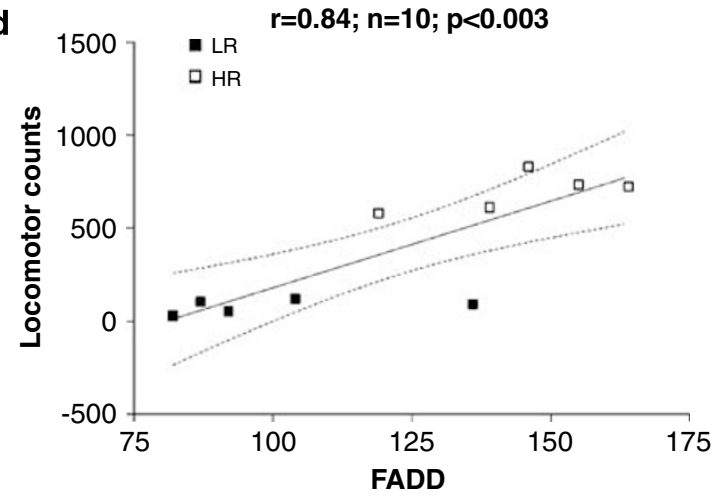

(\% immunoreactivity) b
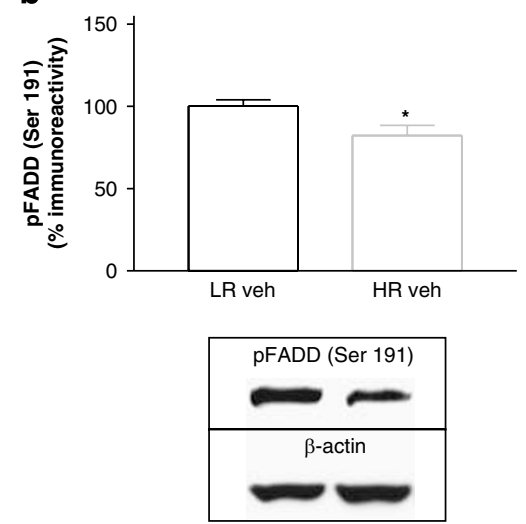

LR veh HR veh
C

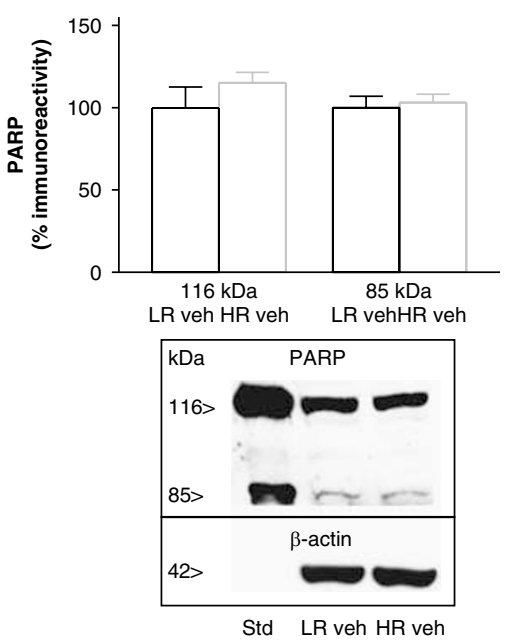

e

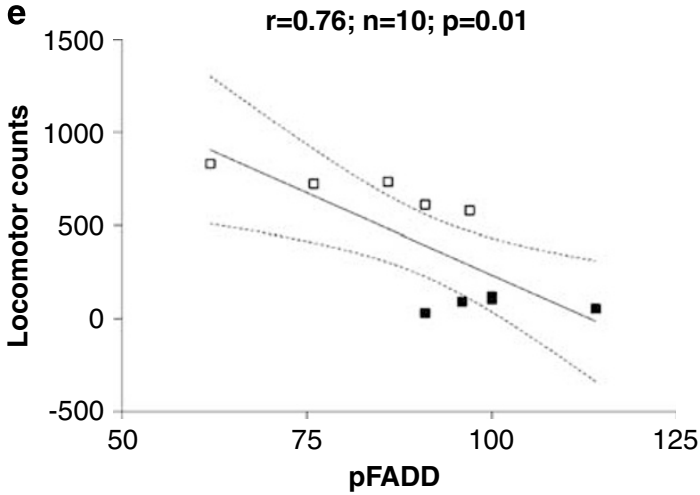

(\% immunoreactivity)

Figure 5 Basal molecular differences in high-responder (HR)/low-responder (LR) rats. (a) Fas-associated protein with death domain (FADD) protein content. Groups of treatments: LR vehicle $(n=5)$, HR vehicle $(n=5)$. Columns are means \pm standard error of the mean (SEM) per group and expressed as percentage of LR vehicle-treated rats. Student's two-tailed t-test detected a significant difference between the groups of treatments: $* * *=0.0070$. (b) pFADD protein content. Student's two-tailed t-test: $* p=0.0395$. (c) Poly-(ADP-ribose) polymerase (PARP) cleavage. Columns are means \pm SEM per group and expressed as percentage of $116 \mathrm{kDa}$-band LR vehicle-treated rats. One-way analysis of variance (ANOVA) did not detect a significant difference between the groups of treatments $(F(3,15)=0.7523, p=0.5379)$. Bottom $(a-c)$ : representative immunoblots of FADD, pFADD, and PARP for each set of experiments, and the corresponding for $\beta$-actin as a loading control (sample: $40 \mu$ g protein). Std, PARP protein standard. The apparent molecular masses were determined as indicated in Figure I. (d) Positive correlation of FADD protein content and locomotion. Scatter plot depicting a significant positive correlation between locomotion scores and the immunodensity of FADD protein in the rat cerebral cortex (same samples) of basal HR and LR rats. Each circle represents a different rat. The solid line $(y=80.81 x+9.33)$ is the best fit of the correlation $(r=0.84, F=18.44, n=10, p<0.003)$. The dotted curves indicate the $95 \%$ confidence interval for the regression line. (e) Negative correlation of pFADD protein content and locomotion. Other details are as above. The solid line $(y=\mid 13.2 x-17.69)$ is the best fit of the correlation $(r=-0.76, F=11.04, n=10, p=0.01)$.

receptors blockade with a selective antagonist increased FADD content in the cortex. This then either suggests a possible serotonergic effect on FADD related to the agonistic properties of $\mathrm{SCH}-23390$ on $5-\mathrm{HT} 1 \mathrm{c} / 2 \mathrm{c}$ receptors or the existence of an endogenous dopaminergic tone activating FADD through $\mathrm{D}_{2}$ receptors when $\mathrm{D}_{1}$ receptors are blocked. Recent studies (Kita et al, 2007) demonstrate that $\mathrm{D}_{2}$ receptors provide a presynaptic component that can not only modulate autoinhibition, but also short-term facilitation of DA release, therefore impacting both $D_{1}$ and $\mathrm{D}_{2}$-mediated postsynaptic plasticity. As for how $\mathrm{D}_{2}$ signal transduction mechanisms modulate FADD activation, it has been previously described that activation of the $\mathrm{D}_{2}$ receptors can activate ERK (Luo et al, 1998; Yan et al, 1999) and also that FADD modulation by opiate drugs was dependent on the activation of the antiapoptotic ERK1/2 signaling pathway (Garcia-Fuster et al, 2007), which suggests ERK as a possible mediator of FADD modulation after $\mathrm{D}_{2}$ receptor activation by cocaine.

\section{Functional Relevance of FADD System Modulation: Individual Differences in a Model of Differential Vulnerability to Drug Abuse}

The second phase of this study utilized selectively bred animals that exhibit marked behavioral differences, including differential propensity to drug-seeking (Piazza et al, 1989; Piazza and Le Moal, 1996). The present study demonstrated that (1) individual differences in noveltyseeking behavior correlated with basal levels of FADD/ pFADD proteins; and that (2) FADD was not differentially regulated in HR/LR rats following repeated cocaine and withdrawal. These results mainly suggest that FADD 


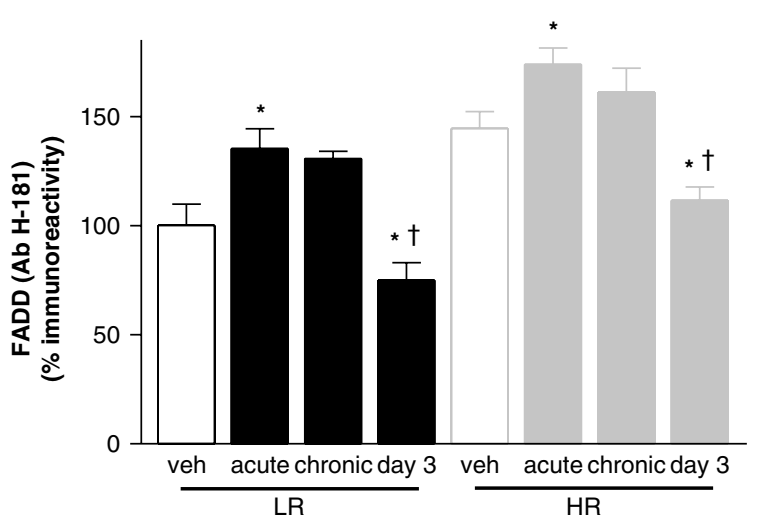

Figure 6 Fas-associated protein with death domain (FADD) is not differentially regulated in high-responder (HR)/low-responder (LR) rats following repeated cocaine and cocaine withdrawal. Groups of treatments: $\mathrm{LR} / \mathrm{HR}$ vehicle $(n=5), \mathrm{LR} / H R$ acute cocaine $(15 \mathrm{mg} / \mathrm{kg}$, i.p., $45 \mathrm{~min} ; n=4)$, $L R / H R$ chronic cocaine ( $15 \mathrm{mg} / \mathrm{kg}$ for 7 days; $n=5)$, and $L R / H R$ chronic cocaine followed by spontaneous withdrawal (day $3 ; n=4-5$ ). Columns are means \pm standard error of the mean (SEM) per group and expressed as percentage of $L R$ vehicle-treated rats. Two-way analysis of variance (ANOVA) detected a significant difference in basal FADD protein content for HR-LR phenotype in all treatment groups, with $\mathrm{HR}$ rats exhibiting higher FADD levels than LR rats (39\% change, $p=0.0002$, two-way ANOVA followed by Bonferroni's post hoc test). There was also a main effect for cocaine over FADD within each phenotype, which paralleled the findings previously observed with commercially purchased rats-ie acute cocaine treatment increased FADD (LR rats: $33 \pm 6 \%$ increase, $p<0.05$; HR rats: $29 \pm 8 \%$ increase, $p<0.05$ ) with a reversal following 3 days of withdrawal (LR rats: $25 \pm 8 \%$ decrease, $p<0.05$; HR rats: $23 \pm 4 \%$ decrease, $p<0.05$ ) (see Figure 3). One-way ANOVA detected significant differences between the groups of treatments if split by group: $* p<0.05$ vs $L R / H R$ vehicle; ${ }^{\dagger} p<0.05$ vs $L R / H R$ cocaine (ANOVA followed by Bonferroni's test). However, no drug $\times$ phenotype interaction was found $(p=0.8567$, n.s. $)$.

signaling could reflect a molecular correlate for the HR/LR phenotype. The basal differences are maintained postcocaine, as cocaine produced an increase in FADD both in HR and LR animals. As we have argued about, a consistent elevation on FADD is likely to promote, even if it does not cause apoptosis (eg impairing mechanisms controlling nonapoptotic functions), potential mechanisms for enhanced neurotoxicity. Therefore, we would hypothesize that HR may be more prone to neurotoxicity to repeated cocaine.

In the present study we show that selectively bred HR/LR rats display baseline differences in the FADD system, with HRs exhibiting higher FADD and lower pFADD levels than LR rats. Notably, HR/LR rats showed similar levels of the basal $116 \mathrm{kDa}$ PARP cleavage ( $\sim 85 \mathrm{kDa}$ fragment) indicating similar rates of basal induction of apoptotic cell death in the cortex. This finding reinforces the notion that the FADD/pFADD system regulates nonapoptotic mechanisms in the brain. Interestingly, the basal changes in FADD/ pFADD protein content were positively and negatively correlated, respectively, with the rats' rates of locomotion activity in a novel environment, suggesting the FADD system as a possible molecular correlate for the HR/LR phenotype. In addition to differences in sensitivity to psychostimulants (Piazza et al, 1989; Piazza and Le Moal, 1996; reviewed in Kabbaj, 2006), HR/LR animals display a variety of other behavioral differences including differences in anxiety behavior (Stead et al, 2006). Thus, future studies will focus on evaluating other behavioral or neuroendocrine measures to determine how they may relate to FADD levels. In the same vein, several prior studies revealed other neurochemical and neural gene expression differences that contribute, at least in part, to the observed HR/LR behavioral phenotypes (Piazza et al, 1991; Hooks et al, 1994a, b; Kabbaj, 2004; Kabbaj et al, 2000; Ballaz et al, 2007a,b). The present observations, together with the $D_{2}$ mechanism involved in FADD modulation and the importance of the dopaminergic system in the regulation of locomotion, point to the possibility that basal HR/LR differences in FADD and pFADD may be driven by differences in dopaminergic circuits (Piazza et al, 1991; Hooks et al, 1994a, b; Dietz et al, 2005). In fact, Flagel et al, 2007, recently showed basal differences in $\mathrm{D}_{2}$ DA-receptor mRNA expression in striatum of selectively bred HR/LR rats. The present study also demonstrated a main effect of cocaine on FADD levels in both HR and LR animals, a finding that paralleled our results in commercially purchased animals - ie increased FADD after acute cocaine with a reversal following 3 days of withdrawal. However, there was no drug $\times$ phenotype interaction, at least with the dosage and method of cocaine administration we used and in our analysis of the response in cortex.

We have focused this work on the cortex as this brain region has been implicated in the cognitive and affective consequences of cocaine, and particularly in the consolidation of the addictive processes (Kalivas and Volkow, 2005). Moreover, the cortex appears critical in the translation of environmental and pharmacological stimuli into adaptative motor responses, including those seen during behavioral sensitization (Pierce and Kalivas, 1997). Of direct relevance to our findings, the cortex exhibits alterations in neural plasticity following cocaine administration (BallesterosYanez et al, 2007), and these plasticity changes, including the novel mechanisms described in our studies, likely mediate critical behavioral sequelae of exposure to cocaine.

Nevertheless, equally relevant changes in the FADD system are likely taking place in subcortical regions and are worthy of further investigation. In particular, HR-LR differences in cocaine's impact on the FADD system may emerge in other brain regions. For instance, previous studies have shown HR animals had an increased DAT function in the NAcc and a decreased DAT function in cortex with no differences on striatum, suggesting a regionspecific role for DAT in mediating information transfer within the corticolimbic circuitry involved in response to novelty (Chefer et al, 2003, Zhu et al, 2007). Therefore, future work should extend the present findings by examining the impact of cocaine on other brain regions in HR and LR rats. Moreover, given the differential propensity of HR $v s$ LR rats for self-administration and our observation of preexisting differences in the FADD system, it will be of great interest to ascertain how well the FADD basal differences correlate with drug-seeking behavior and with the development of long-term addiction.

\section{ACKNOWLEDGEMENTS}

This study was supported by NIH fundings RO1DA13386, 5P01MH42251, 5P01DA021633-02, Conte Center grant no. L99MH60398, and Office of Naval Research (ONR) N00014- 
02-1-0879 to HA and SJW. We thank Dr Jesús A GarcíaSevilla and Dr Shelly B Flagel for useful comments and Sharon Burke and Jennifer Fitzpatrick for excellent technical assistance.

\section{DISCLOSURE/CONFLICT OF INTEREST}

The authors state no conflict of interest.

\section{REFERENCES}

Abdolzade-Bavil A, Hayes S, Goretzki L, Kroger M, Anders J, Hendriks R (2004). Convenient and versatile subcellular extraction procedure, that facilitates classical protein expression profiling and functional protein analysis. Proteomics 4: 1397-1405.

Alappat EC, Feig C, Boyerinas B, Volkland J, Samuels M, Murmann $\mathrm{AE}$ et al (2005). Phosphorylation of FADD at serine 194 by CKIalpha regulates its nonapoptotic activities. Mol Cell 19: 321-332.

Algeciras-Schimnich A, Shen L, Barnhart BC, Murmann AE, Burkhardt JK, Peter ME (2002). Molecular ordering of the initial signaling events of CD95. Mol Cell Biol 22: 207-220.

Ballaz SJ, Akil H, Watson SJ (2007a). Analysis of 5-HT6 and 5-HT7 receptor gene expression in rats showing differences in noveltyseeking behavior. Neuroscience 147: 428-438.

Ballaz SJ, Akil H, Watson SJ (2007b). The CCK-system mediates adaptation to novelty-induced stress in the rat: a pharmacological evidence. Neurosci Lett 428: 27-32.

Ballesteros-Yanez I, Valverde O, Ledent C, Maldonado R, DeFelipe $\mathrm{J}$ (2007). Chronic cocaine treatment alters dendritic arborization in the adult motor cortex through a CB1 cannabinoid receptordependent mechanism. Neuroscience 146: 1536-1545.

Barry U, Zuo Z (2005). Opioids: old drugs for potential new applications. Curr Pharm Des 11: 1343-1350.

Beisner DR, Chu IH, Arechiga AF, Hedrick SM, Walsh CM (2003). The requirements for Fas-associated death domain signaling in mature T cell activation and survival. J Immunol 171: 247-256.

Beitner-Johnson D, Nestler EJ (1991). Morphine and cocaine exert common chronic actions on tyrosine hydroxylase in dopaminergic brain reward regions. J Neurochem 57: 344-347.

Berke JD, Hyman SE (2000). Addiction, dopamine, and the molecular mechanisms of memory. Neuron 25: 515-532.

Bhojani MS, Chen G, Ross BD, Beer DG, Rehemtulla A (2005). Nuclear localized phosphorylated FADD induces cell proliferation and is associated with aggressive lung cancer. Cell Cycle 4: $1478-1481$.

Bi FF, Xiao B, Hu YQ, Tian FF, Wu ZG, Ding L et al (2008). Expression and localization of Fas-associated proteins following focal cerebral ischemia in rats. Brain Res 1191: 30-38.

Cagnol S, Van Obberghen-Schilling E, Chambard JC (2006). Prolonged activation of ERK1,2 induces FADD-independent caspase 8 activation and cell death. Apoptosis 11: 337-346.

Cameron HA, Hazel TG, McKay RD (1998). Regulation of neurogenesis by growth factors and neurotransmitters. J Neurobiol 36: 287-306.

Chefer VI, Zakharova I, Shippenberg TS (2003). Enhanced responsiveness to novelty and cocaine is associated with decreased basal dopamine uptake and release in the nucleus accumbens: quantitative microdialysis in rats under transient conditions. J Neurosci 23: 3076-3084.

Chen G, Bhojani MS, Heaford AC, Chang DC, Laxman B, Thomas DG et al (2005). Phosphorylated FADD induces NF-kappaB, perturbs cell cycle, and is associated with poor outcome in lung adenocarcinomas. Proc Natl Acad Sci USA 102: 12507-12512.

Cunha-Oliveira T, Rego AC, Cardoso SM, Borges F, Swerdlow RH, Macedo $\mathrm{T}$ et al (2006). Mitochondrial dysfunction and caspase activation in rat cortical neurons treated with cocaine or amphetamine. Brain Res 1089: 44-54.
Desbarats J, Birge RB, Mimouni-Rongy M, Weinstein DE, Palerme JS, Newell MK (2003). Fas engagement induces neurite growth through ERK activation and p35 upregulation. Nat Cell Biol 5: $118-125$.

Dey S, Snow DM (2007). Cocaine exposure in vitro induces apoptosis in fetal locus coeruleus neurons through TNF-alphamediated induction of Bax and phosphorylated c-Jun $\mathrm{NH}(2)$ terminal kinase. J Neurochem 103: 542-556.

Di Chiara G, Imperato A (1988). Drugs abused by humans preferentially increase synaptic dopamine concentrations in the mesolimbic system of freely moving rats. Proc Natl Acad Sci USA 85: 5274-5278.

Dietrich JB, Mangeol A, Revel MO, Burgun C, Aunis D, Zwiller J (2005). Acute or repeated cocaine administration generates reactive oxygen species and induces antioxidant enzyme activity in dopaminergic rat brain structures. Neuropharmacology 48: 965-974.

Dietz DM, Tapocik J, Gaval-Cruz M, Kabbaj M (2005). Dopamine transporter, but not tyrosine hydroxylase, may be implicated in determining individual differences in behavioral sensitization to amphetamine. Physiol Behav 86: 347-355.

Flagel SB, Clinton SM, Watson SJ, Robinson TE, Akil H (ed) (2007). Rats selectively bred on the basis of a novelty-seeking trait exhibit individual differences in the propensity to approach signals vs. goals: implications for addiction. Society for Neuroscience Annual Meeting. San Diego, CA: San Diego, CA.

Fumagalli F, Bedogni F, Maragnoli ME, Gennarelli M, Perez J, Racagni $G$ et al (2003). Dopaminergic D2 receptor activation modulates FGF-2 gene expression in rat prefrontal cortex and hippocampus. J Neurosci Res 74: 74-80.

Fumagalli F, Pasquale L, Racagni G, Riva MA (2006). Dynamic regulation of fibroblast growth factor 2 (FGF-2) gene expression in the rat brain following single and repeated cocaine administration. J Neurochem 96: 996-1004.

Garcia-Fuster MJ, Ferrer-Alcon M, Miralles A, Garcia-Sevilla JA (2003). Modulation of Fas receptor proteins and dynamin during opiate addiction and induction of opiate withdrawal in rat brain. Naunyn Schmiedebergs Arch Pharmacol 368: 421-431.

Garcia-Fuster MJ, Miralles A, Garcia-Sevilla JA (2007). Effects of opiate drugs on Fas-associated protein with death domain (FADD) and effector caspases in the rat brain: regulation by the ERK1/2 MAP kinase pathway. Neuropsychopharmacology 32: 399-411.

Gomez-Angelats M, Cidlowski JA (2003). Molecular evidence for the nuclear localization of FADD. Cell Death Differ 10: 791-797.

Gosnell BA (2005). Sucrose intake enhances behavioral sensitization produced by cocaine. Brain Res 1031: 194-201.

Holmstrom TH, Schmitz I, Soderstrom TS, Poukkula M, Johnson VL, Chow SC et al (2000). MAPK/ERK signaling in activated T cells inhibits CD95/Fas-mediated apoptosis downstream of DISC assembly. EMBO J 19: 5418-5428.

Holmstrom TH, Tran SE, Johnson VL, Ahn NG, Chow SC, Eriksson JE (1999). Inhibition of mitogen-activated kinase signaling sensitizes HeLa cells to Fas receptor-mediated apoptosis. Mol Cell Biol 19: 5991-6002.

Hooks MS, Juncos JL, Justice Jr JB, Meiergerd SM, Povlock SL, Schenk JO et al (1994a). Individual locomotor response to novelty predicts selective alterations in D1 and D2 receptors and mRNAs. J Neurosci 14: 6144-6152.

Hooks MS, Sorg BA, Kalivas PW (1994b). The relationship between MRNA levels and the locomotor response to novelty. Brain Res 663: 312-316.

Hu S, Cheeran MC, Sheng WS, Ni HT, Lokensgard JR, Peterson PK (2006). Cocaine alters proliferation, migration, and differentiation of human fetal brain-derived neural precursor cells. J Pharmacol Exp Ther 318: 1280-1286.

Imam SZ, Duhart HM, Skinner JT, Ali SF (2005). Cocaine induces a differential dose-dependent alteration in the expression profile 
of immediate early genes, transcription factors, and caspases in PC12 cells: a possible mechanism of neurotoxic damage in cocaine addiction. Ann NY Acad Sci 1053: 482-490.

Isgor C, Cecchi M, Kabbaj M, Akil H, Watson SJ (2003). Estrogen receptor beta in the paraventricular nucleus of hypothalamus regulates the neuroendocrine response to stress and is regulated by corticosterone. Neuroscience 121: 837-845.

Kabbaj M (2004). Neurobiological bases of individual differences in emotional and stress responsiveness: high responders-low responders model. Arch Neurol 61: 1009-1012.

Kabbaj M (2006). Individual differences in vulnerability to drug abuse: the high responders/low responders model. CNS Neurol Disord Drug Targets 5: 513-520.

Kabbaj M, Akil H (2001). Individual differences in novelty-seeking behavior in rats: a c-fos study. Neuroscience 106: 535-545.

Kabbaj M, Devine DP, Savage VR, Akil H (2000). Neurobiological correlates of individual differences in novelty-seeking behavior in the rat: differential expression of stress-related molecules. J Neurosci 20: 6983-6988.

Kalivas PW (2007). Neurobiology of cocaine addiction: implications for new pharmacotherapy. Am J Addict 16: 71-78.

Kalivas PW, Volkow ND (2005). The neural basis of addiction: a pathology of motivation and choice. Am J Psychiatry 162: 1403-1413.

Kischkel FC, Hellbardt S, Behrmann I, Germer M, Pawlita M, Krammer PH et al (1995). Cytotoxicity-dependent APO-1 (Fas/ CD95)-associated proteins form a death-inducing signaling complex (DISC) with the receptor. EMBO J 14: 5579-5588.

Kita JM, Parker LE, Phillips PE, Garris PA, Wightman RM (2007). Paradoxical modulation of short-term facilitation of dopamine release by dopamine autoreceptors. J Neurochem 102: 1115-1124.

Kreek MJ (1996). Cocaine, dopamine and the endogenous opioid system. J Addict Dis 15: 73-96.

Lee KH, Feig C, Tchikov V, Schickel R, Hallas C, Schutze S et al (2006). The role of receptor internalization in CD95 signaling. EMBO J 25: 1009-1023.

Luo Y, Kokkonen GC, Wang X, Neve KA, Roth GS (1998). D2 dopamine receptors stimulate mitogenesis through pertussis toxin-sensitive G proteins and Ras-involved ERK and SAP/JNK pathways in rat C6-D2L glioma cells. J Neurochem 71: 980-990.

Marinelli M, White FJ (2000). Enhanced vulnerability to cocaine self-administration is associated with elevated impulse activity of midbrain dopamine neurons. J Neurosci 20: 8876-8885.

Nassogne MC, Louahed J, Evrard P, Courtoy PJ (1997). Cocaine induces apoptosis in cortical neurons of fetal mice. J Neurochem 68: 2442-2450.

Nestler EJ (2001). Molecular basis of long-term plasticity underlying addiction. Nat Rev Neurosci 2: 119-128.

Nestler EJ (2004). Molecular mechanisms of drug addiction. Neuropharmacology 47(Suppl 1): 24-32.

Nestler EJ (2005). Is there a common molecular pathway for addiction? Nat Neurosci 8: 1445-1449.

O’Reilly LA, Divisekera U, Newton K, Scalzo K, Kataoka T, Puthalakath $\mathrm{H}$ et al (2004). Modifications and intracellular trafficking of FADD/MORT1 and caspase-8 after stimulation of T lymphocytes. Cell Death Differ 11: 724-736.

Park HH, Lo YC, Lin SC, Wang L, Yang JK, Wu H (2007). The death domain superfamily in intracellular signaling of apoptosis and inflammation. Annu Rev Immunol 25: 561-586.

Park SM, Schickel R, Peter ME (2005). Nonapoptotic functions of FADD-binding death receptors and their signaling molecules. Curr Opin Cell Biol 17: 610-616.

Peter ME, Budd RC, Desbarats J, Hedrick SM, Hueber AO, Newell MK et al (2007). The CD95 receptor: apoptosis revisited. Cell 129: 447-450.

Piazza PV, Deminiere JM, Le Moal M, Simon H (1989). Factors that predict individual vulnerability to amphetamine self-administration. Science 245: 1511-1513.
Piazza PV, Le Moal ML (1996). Pathophysiological basis of vulnerability to drug abuse: role of an interaction between stress, glucocorticoids, and dopaminergic neurons. Annu Rev Pharmacol Toxicol 36: 359-378.

Piazza PV, Rouge-Pont F, Deminiere JM, Kharoubi M, Le Moal M, Simon H (1991). Dopaminergic activity is reduced in the prefrontal cortex and increased in the nucleus accumbens of rats predisposed to develop amphetamine self-administration. Brain Res 567: 169-174.

Pierce RC, Kalivas PW (1997). A circuitry model of the expression of behavioral sensitization to amphetamine-like psychostimulants. Brain Res Brain Res Rev 25: 192-216.

Pierre PJ, Vezina P (1997). Predisposition to self-administer amphetamine: the contribution of response to novelty and prior exposure to the drug. Psychopharmacology (Berl) 129: 277-284.

Robinson TE, Kolb B (2004). Structural plasticity associated with exposure to drugs of abuse. Neuropharmacology 47(Suppl 1): 33-46.

Roceri M, Molteni R, Fumagalli F, Racagni G, Gennarelli M, Corsini G et al (2001). Stimulatory role of dopamine on fibroblast growth factor-2 expression in rat striatum. J Neurochem 76: 990-997.

Screaton RA, Kiessling S, Sansom OJ, Millar CB, Maddison K, Bird A et al (2003). Fas-associated death domain protein interacts with methyl-CpG binding domain protein 4: a potential link between genome surveillance and apoptosis. Proc Natl Acad Sci USA 100: 5211-5216.

Sommer L, Rao M (2002). Neural stem cells and regulation of cell number. Prog Neurobiol 66: 1-18.

Stead JD, Clinton S, Neal C, Schneider J, Jama A, Miller S et al (2006). Selective breeding for divergence in novelty-seeking traits: heritability and enrichment in spontaneous anxietyrelated behaviors. Behav Genet 36: 697-712.

Tegeder I, Geisslinger G (2004). Opioids as modulators of cell death and survival - unraveling mechanisms and revealing new indications. Pharmacol Rev 56: 351-369.

Wise RA, Bozarth MA (1985). Brain mechanisms of drug reward and euphoria. Psychiatr Med 3: 445-460.

Yamaguchi M, Suzuki T, Seki T, Namba T, Liu J, Arai H et al (2005). Decreased cell proliferation in the dentate gyrus of rats after repeated administration of cocaine. Synapse 58: 63-71.

Yan Z, Feng J, Fienberg AA, Greengard P (1999). D(2) dopamine receptors induce mitogen-activated protein kinase and cAMP response element-binding protein phosphorylation in neurons. Proc Natl Acad Sci USA 96: 11607-11612.

Yoo NJ, Lee SH, Jeong EG, Lee JW, Soung YH, Nam SW et al (2007). Expression of nuclear and cytoplasmic phosphorylated FADD in gastric cancers. Pathol Res Pract 203: 73-78.

Zhang GC, Mao LM, Liu XY, Parelkar NK, Arora A, Yang L et al (2007). In vivo regulation of Homerla expression in the striatum by cocaine. Mol Pharmacol 71: 1148-1158.

Zhang J, Cado D, Chen A, Kabra NH, Winoto A (1998). Fasmediated apoptosis and activation-induced T-cell proliferation are defective in mice lacking FADD/Mort1. Nature 392: 296-300.

Zhang Y, Rosenberg S, Wang H, Imtiyaz HZ, Hou YJ, Zhang J (2005). Conditional Fas-associated death domain protein (FADD): GFP knockout mice reveal FADD is dispensable in thymic development but essential in peripheral $\mathrm{T}$ cell homeostasis. J Immunol 175: 3033-3044.

Zhu J, Bardo MT, Bruntz RC, Stairs DJ, Dwoskin LP (2007). Individual differences in response to novelty predict prefrontal cortex dopamine transporter function and cell surface expression. Eur J Neurosci 26: 717-728.

Zuliani C, Kleber S, Klussmann S, Wenger T, Kenzelmann M, Schreglmann $\mathrm{N}$ et al (2006). Control of neuronal branching by the death receptor CD95 (Fas/Apo-1). Cell Death Differ 13: $31-40$. 